\section{Commentary: The elephant in the room: Walking the walk and talking the talk after a frozen elephant trunk procedure}

\author{
Xiaoying Lou, MD, and Edward P. Chen, MD
}

The frozen elephant trunk (FET) operation, initially proposed by Kato and colleagues in 1996, involves open reconstruction of the proximal aorta with a conventional Dacron prosthesis and a distally secured self-expanding endovascular prosthesis. FET provides a landing zone for repair of residual distal aortic pathology; however, procedural complexity and the potentially increased risk of neurologic complications along with the lack of available outcomes data may limit widescale implementation.

The Baylor group have conducted a meta-analysis of more than 3154 patients to better quantify adverse neurologic events after FET. ${ }^{2}$ The importance of addressing these concerns is predicated on the fact that previous studies have been limited to small series. We commend the authors for synthesizing together the available literature to better define the safety profile of FET.

Operative mortality, stroke, and spinal cord ischemia (SCI) rates in this analysis were found to be $8.8 \%, 7.6 \%$, and $4.7 \%$, respectively. Mortality and stroke rates were slightly greater than the $7.7 \%$ and $6.5 \%$ rates reported after FET in a previous meta-analysis but still lower than the $14.5 \%$ and $9.7 \%$ rates observed after conventional elephant trunk. ${ }^{3}$ Although the rates of SCI after FET were comparable in both reports, they were greater than the $2.6 \%$ rate reported after conventional elephant trunk. ${ }^{3}$ SCI differences may be partially explained by the fact that implanting a FET stent-graft seals the proximal descending aorta, potentially compromising cord blood supply and thereby increasing the risk of SCI. ${ }^{4}$

\footnotetext{
From the Division of Cardiothoracic Surgery, Emory University School of Medicine, Atlanta, Ga.

Disclosures: Authors have nothing to disclose with regard to commercial support.

Received for publication Oct 27, 2019; revisions received Oct 27, 2019; accepted for publication Oct 28, 2019; available ahead of print Nov 20, 2019.

Address for reprints: Edward P. Chen, MD, Division of Cardiothoracic Surgery, Emory University School of Medicine, 1365 Clifton Rd NE, Atlanta, GA 30322 (E-mail: edward.p.chen@emory.edu).

J Thorac Cardiovasc Surg 2020;160:34-5

0022-5223/\$36.00

Copyright (c) 2019 by The American Association for Thoracic Surgery

https://doi.org/10.1016/j.jtcvs.2019.10.166
}

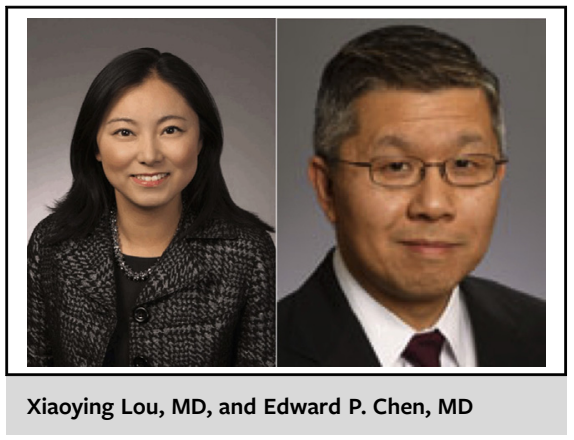

CENTRAL MESSAGE

FET may increase risk of spinal cord ischemia with extended stent coverage and should be used cautiously in acute type A dissection. RCTs are needed to guide best practice as FET gains widespread use.

The most unique and important aspect of this manuscript are the 2 subanalyses performed examining the impact of FET length on SCI as well as the impact of emergent operative status on adverse events. SCI incidence was greater in studies employing stent length $\geq 15 \mathrm{~cm}$ or coverage to/ beyond T8 compared with $10-\mathrm{cm}$ length $(11.6 \%$ vs $2.5 \%$, $P<.001)$. In addition, a nonsignificant increase in adverse events after FET in acute type A dissection was found versus nonacute dissection/aneurysm cases.

No distinction was able to be made between permanent versus transient SCI, and use of cerebrospinal fluid drainage and circulatory arrest temperature were unable to be reported. It is unclear whether these adjuncts would provide further protection against SCI. In our experience, a strategy of permissive hypertension and selective lumbar drain use may rescue patients who develop postoperative SCI after endograft coverage in distal aortic dissections. ${ }^{5}$

Finally, it is important to mention that FET is more likely to be performed in specialized aortic centers, which may explain the insignificant differences in adverse rates between emergent and nonemergent cases. These data may not reflect how the device will perform in lessexperienced centers as the procedure gains more widespread use, as the learning curve for FET can have a significant impact on hospital mortality and midterm survival. ${ }^{6}$ The authors also acknowledge that there may have been overlap in timing between elective and emergent cases, as 
no standardized definitions with respect to case urgency were used.

This study represents an important contribution to our current understanding of the safety profile of FET and provides new insights in the factors associated with SCI. Perhaps the stage is now set for future randomized controlled trials with long-term follow-up to establish standardized indications and protocols for this potentially transformative procedure.

\section{References}

1. Kato M, Ohnishi K, Kaneko M, Ueda T, Kishi D, Mizushima T, et al. New graft implanting method for thoracic aortic aneurysm or dissection with a stented graft. Circulation. 1996;94:II188-93.
2. Preventza O, Liao JL, Olive JK, Simpson K, Critsinelis AC, Price MD, et al Neurologic complications after the frozen elephant trunk procedure: a metaanalysis of more than 3000 patients. J Thorac Cardiovasc Surg. 2020;160: 20-33.e4.

3. Hanif H, Dubois L, Ouzounian M, Peterson MD, El-Hamamsy I, Dagenais F, et al Aortic arch reconstructive surgery with conventional techniques vs frozen elephant trunk: a systematic review and meta-analysis. Can J Cardiol. 2018;34: 262-73.

4. Hagl C, Pichlmaier M, Khaladj N. Elephant trunks in aortic surgery: fresh and frozen. J Thorac Cardiovasc Surg. 2013;145: S98-102.

5. Leshnower BG, Chen EP. TEVAR for acute complicated Type B aortic dissection. Op Tech Thorac Cardiovasc Surg. 2018;23:21-33.

6. Dinato FJ, Dias RR, Duncan JA, Fernandes F, Ramires FJA, Mady C, et al. The learning curve effect on outcomes with frozen elephant trunk technique for extensive thoracic aorta disease. J Card Surg. 2019;34: 796-802.
See Article page 20.

\section{Commentary: Is it time to thaw the frozen elephant trunk procedure?}

\author{
Nicholas T. Kouchoukos, MD
}

Since its introduction into clinical practice in the late 1990s, the frozen elephant trunk (FET) procedure has become a widely used method of repair for extensive intrathoracic aortic disease that requires replacement of the aortic arch, including acute aortic dissection. In this issue of The Journal of Thoracic and Cardiovascular Surgery, Preventza and colleagues ${ }^{1}$ present the results of a meta-analysis of more than 3000 patients from 35 studies who had undergone FET procedures, focusing on early mortality and the risks of stroke and spinal cord ischemic injury (SCI). The pooled estimates for operative mortality, stroke, and SCI were $8.8 \%, 7.6 \%$, and $4.7 \%$ respectively, and are comparable to those from 2 previously published meta-analyses. ${ }^{2,3}$ The prevalence of SCI is of particular importance, because the rates reported $(4.7 \%$ in the current study of Preventza and colleagues, ${ }^{1} 5.1 \%$ in the study of Tian and colleagues, ${ }^{2}$

\footnotetext{
From the Division of Cardiovascular and Thoracic Surgery, Missouri Baptist Medical Center, BJC Healthcare, St Louis, Mo.

Disclosures: Author has nothing to disclose with regard to commercial support.

Received for publication Oct 24, 2019; revisions received Oct 24, 2019; accepted for publication Oct 24, 2019; available ahead of print Nov 14, 2019

Address for reprints: Nicholas T. Kouchoukos, MD, Missouri Baptist Medical Center, 3023 N Ballas Rd, Suite 150D, St Louis, MO 63131 (E-mail: ntkouch@aol.com). J Thorac Cardiovasc Surg 2020;160:35-6 $0022-5223 / \$ 36.00$

Copyright (c) 2019 by The American Association for Thoracic Surgery https://doi.org/10.1016/j.jtcvs.2019.10.135
}

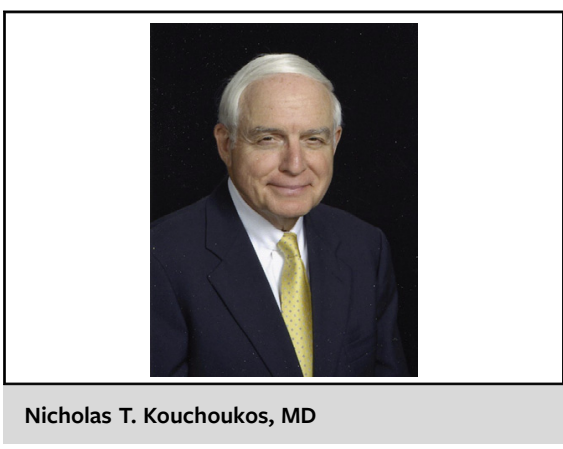

CENTRAL MESSAGE

Extensive analysis continues to indicate that spinal cord ischemic injury is an important complication of the frozen elephant trunk technique for repair of extensive thoracic aortic disease.

and $5.0 \%$ in the report of Hanif and colleagues ${ }^{3}$ ) are higher than those reported for the classic elephant trunk procedure, for 1-stage procedures performed without a stent graft, and for conventional aortic arch procedures. ${ }^{3-7}$

Some important limitations of the current study that were acknowledged by Preventza and colleagues ${ }^{1}$ deserve comment. Age of the patients was not analyzed separately. In the 16 studies originating from China, the mean age ranged from 44 to 54 years. Thirteen of these 16 studies reported a rate of SCI of $2.5 \%$ or less, and 10 studies reported a rate of $0 \%$. In the 7 series reported from Japan, the mean 